\title{
25 Research Soure \\ Medical Education Interest, Exposure, and Career Planning in Subspecialty Trainees
}

Ariela L Marshall ( $\square$ marshall.ariela@mayo.edu )

Mayo Clinic Minnesota https://orcid.org/0000-0001-7388-0422

Carrie A. Thompson

Mayo Clinic Minnesota

Michael W. Cullen

Mayo Clinic Minnesota

\section{Laura E. Raffals}

Mayo Clinic Minnesota

Amy S. Oxentenko

Mayo Clinic Minnesota

\section{Research article}

Keywords: Medical education, training, fellowship

Posted Date: January 23rd, 2020

DOI: https://doi.org/10.21203/rs.2.21656/v1

License: (c) (1) This work is licensed under a Creative Commons Attribution 4.0 International License. Read Full License

Version of Record: A version of this preprint was published at Medical Science Educator on June 10th, 2020. See the published version at https://doi.org/10.1007/s40670-020-01007-x. 


\section{Abstract}

\section{Background}

Medical education encompasses many activities (e.g., teaching, supervision, mentorship, and administration). Little research has explored what the term "medical education" means to trainees or assessed the importance postgraduate medical trainees place on education as part of their career plans.

\section{Methods}

We conducted a survey of fellows in all subspecialty training programs at a three-site academic institution. We asked multiple choice and Likert scale questions to characterize fellows' perception of, interest and training in medical education.

Results

One hundred sixty-nine of 530 (31.9\%) fellows responded. Fellows were training in subspecialties of internal medicine (49.7\%) and surgery (13.0\%), among others. Most fellows planned careers in academic medicine (38.5\% clinician-educator, $22.5 \%$ clinician-investigator, $17.2 \%$ academic clinician). Fellows reported that their conception of medical education involved supervising trainees in a clinical capacity (93.5\%), teaching in the classroom (89.3\%), and providing mentorship for trainees (87.6\%). Respondents identified "being an educator" as extremely (43.8\%) or moderately (43.2\%) important for their future careers. Only $30.2 \%$ had received formal training in medical education, but $61.5 \%$ felt that formal training should be required for those pursuing careers with strong educational components.

\section{Conclusions}

Most subspecialty fellows surveyed planned careers in academics and felt that medical education was important to their professional future. While less than a third received formal training in education, almost two thirds felt that such training should be required for a career as an educator. This study provides evidence for the creation and promotion of educational training programs for trainees interested in careers involving medical education.

\section{Background}

Medical trainees, particularly those intending to pursue careers in academic medicine, require skills in education and teaching. Some institutions support programs to "teach the teachers" or "train the trainers" at the resident-physician level. Such programs are less prevalent at the subspecialty fellow level and, when available, generally focus on a single subspecialty training program."'m Assessing the attitudes and skills of subspecialty fellows regarding medical education is particularly important, as these trainees will soon enter independent practice as clinicians and educators. 
Additionally, the phrase "medical education" itself encompasses many activities including clinical teaching and supervision, mentorship, administration of an educational program, and a variety of other activities. Little research has explored what the term "medical education" means to trainees and its role in their future career. In this study, our aims were to characterize subspecialty fellows' perception of, interest and training in medical education.

\section{Methods}

We conducted an IRB-approved, survey-based study of fellows in all subspecialty training programs at three Mayo Clinic sites (Minnesota, Arizona, and Florida) using a Google Documents online survey tool. An email invitation to participate was sent in October 2018 to all subspecialty fellows at the three sites, with assurance that participation was voluntary and all answers would be anonymous. A reminder email was sent to all fellows after 7,14 , and 21 days, and the survey remained open for a total of 28 days.

No validated survey tool for assessing interest and experience in medical education training and exposure exists. Therefore, survey questions were developed specifically for this study by the principal investigator and edited based on the input of four individuals with experience in both survey research and/or subspecialty fellowship training program leadership. Survey questions consisted of multiple choice and Likert-scale questions and all questions are included in the Supplemental File. For the question, "What does the term 'medical education' mean to you?" and "What type of formal training in medical education have you received?" fellows could select more than one answer (and therefore, percentages to these responses do not total $100 \%$ ). For all other questions, respondents could select only a single answer. Survey responses were analyzed using Google Docs and JMP and summarized using descriptive statistics.

\section{Results}

Of 530 fellows contacted by email, 169 responded (response rate 31.9\%). Respondent demographics are shown in Table 1. Respondents were more often men (58\%), and identified as white (46.4\%), Asian $(28.3 \%)$ or Hispanic $(10.2 \%)$. Respondents were training in a variety of subspecialties, most frequently within internal medicine (49.7\%) and surgery (13\%). Most planned on careers in academic medicine (38.5\% clinician-educator, $22.5 \%$ clinician-investigator, $17.2 \%$ academic clinician).

Responses to questions about medical education are shown in Table 2. Fellows reported that their conception of medical education involved supervising trainees in a clinical capacity (93.5\%), teaching in the classroom (89.3\%), providing mentorship for trainees (87.6\%), holding leadership roles in education (63.3\%), and conducting research in education (56.2\%). The majority of fellows (62.7\%) felt that the primary definition was supervising in the clinical capacity.

Respondents identified "being an educator" as extremely (37.3\%) or moderately (47.9\%) important during fellowship and extremely (43.8\%) or moderately (43.2\%) important for their future careers. There were 
$30.2 \%$ of respondents who had received formal training in medical education, which was primarily coursework, not leading to a formal degree/certificate. Overall, $61.5 \%$ felt that formal training in education should be required for those pursuing a career as a medical educator or clinician-educator.

\section{Discussion}

We conducted a survey of fellows across multiple specialties at a large tri-site academic medical center and found that fellows had a wide variety of conceptions of what "medical education" means, ranging from supervising trainees and teaching in the classroom to providing mentorship, holding leadership roles in education and conducting medical education research. Most fellows felt that being an educator would be extremely or moderately important in their future careers, but relatively few had received formal training in education. Many felt that formal training in medical education should be required for those pursuing a career as an educator.

Our findings highlight the importance subspecialty fellows place on medical education as part of their future careers and the current lack of availability of training in education. Prior research has demonstrated that positive clinical experiences and exposure to/interaction with mentors and role models impacts career choice both at the resident and fellow level.' Medical education training programs for residents have led to increased interest in teaching and increased positive self-perception of teaching skills. ${ }^{1}$ It is therefore reasonable to postulate that formal training in medical education may positively influence trainees' interest in and pursuit of excellence in medical education. Additional programs at the fellowship level have the potential to elevate the importance of teaching and have a positive impact both on trainees as well as patients. ${ }^{2}$ "Programs which focus on teaching for trainees at multiple levels from medical school through fellowship may have the potential to create a community of medical educators and expand exposure and interest at all levels.'

Unfortunately, there is a lack of formal curricula in teaching skills in most subspecialty training programs, with time, financial resources, and lack of availability of expert faculty cited as barriers to implementation. A recent survey of internal medicine subspecialty fellows found, similar to our study, that most trainees had no specific teaching-focused training or feedback on their teaching skills during fellowship, but that most anticipated teaching to be part of their future careers. These internal medicine subspecialty fellows expressed interest in programs that could improve their teaching skills.

Our study has several limitations. The survey was conducted at a single (albeit, three-site) institution where the majority of participants reported that they planned careers in academic medicine, particularly as clinician-educators. This, along with the response rate, may reflect selection bias, such that those fellows who choose to participate may place more importance on medical education, which may limit generalizability. Additionally, we were not able to assess actual (instead, we assessed planned) career outcomes after fellowship training in order to determine how many fellows were able to actualize their planned career paths. These are areas that could be investigated further in future studies. 


\section{Conclusions}

A majority of fellows in a broad range of subspecialties reported that medical education was somewhat or very important for their future career plans, and many anticipated careers as medical educators. While less than one-third of fellows completed formal training in medical education, almost two-thirds felt that such training should be required for those planning education-based careers. We hope that this survey provides further evidence of the need to broaden and promote medical education training for subspecialty trainees, particularly for those interested in careers as educators.

\section{Declarations}

Ethics approval:

This study was granted IRB approval by the Mayo Clinic IRB, and consent to participate was deemed unnecessary (waived) by the Mayo Clinic IRB.

Consent for publication

Not applicable

Availability of data and materials

The datasets used and/or analysed during the current study are available from the corresponding author on reasonable request.

Competing interests:

The authors declare that they have no competing interests.

Funding:

No funding was provided/utilized for this study.

Authors' contributions:

ALM formulated the study question and design, collected and analyzed the data, interpreted the data, wrote and critically reviewed the manuscript, CAT interpreted the data and critically reviewed the manuscript, MWC interpreted the data and critically reviewed the manuscript, LER interpreted the data and critically reviewed the manuscript, ASO oversaw the overall study process, interpreted the data and critically reviewed the manuscript. All authors read and approved the final manuscript.

Acknowledgements:

Not applicable

\section{Tables}




\begin{tabular}{|c|c|}
\hline & $\mathbf{N}(\%)$ \\
\hline \multicolumn{2}{|l|}{ Sex } \\
\hline Men & $98(58 \%)$ \\
\hline Women & $69(40.8 \%)$ \\
\hline Prefer not to say & $2(1.2 \%)$ \\
\hline \multicolumn{2}{|l|}{ Race } \\
\hline African & $4(2.4 \%)$ \\
\hline Asian & $47(28.3 \%)$ \\
\hline Hispanic & $17(10.2 \%)$ \\
\hline White & $77(46.4 \%)$ \\
\hline Prefer not to say & $15(9 \%)$ \\
\hline Other & $9(5.3 \%)$ \\
\hline \multicolumn{2}{|l|}{ Subspecialty area } \\
\hline Anesthesia & $7(4.1 \%)$ \\
\hline Internal Medicine & $84(49.7 \%)$ \\
\hline Neurology & $13(7.7 \%)$ \\
\hline Opthalmology & $2(1.2 \%)$ \\
\hline OB-GYN & $7(4.1 \%)$ \\
\hline Pathology & $11(6.5 \%)$ \\
\hline Pediatrics & $9(5.3 \%)$ \\
\hline Psychiatry & $3(1.8 \%)$ \\
\hline Radiology & $6(3.6 \%)$ \\
\hline Surgical & $22(13.0 \%)$ \\
\hline Other & $5(3.0 \%)$ \\
\hline \multicolumn{2}{|l|}{ Planned Career Path } \\
\hline Academic Medicine: Clinician & $29(17.2 \%)$ \\
\hline Academic Medicine: Clinician-Educator & $63(38.5 \%)$ \\
\hline Academic Medicine: Clinician-Investigator & $38(22.5 \%)$ \\
\hline
\end{tabular}




\begin{tabular}{|l|l|} 
Community/Private Practice & $26(15.4 \%)$ \\
\hline Hybrid (Private/Academic) & $1(0.6 \%)$ \\
\hline Non-Clinical: Industry/Pharmaceutical & $1(0.6 \%)$ \\
Unknown & $9(5.3 \%)$ \\
Other & $2(1.2 \%)$ \\
\hline
\end{tabular}


Table 2: Responses Regarding Medical Education

$N(\%)$

What does the term "medical education" mean to you?

Supervising medical students/trainees in a clinical capacity

158

Teaching medical students/trainees in a classroom or other formal curricular setting (non-clinical)

Mentorship/career development for medical students/trainees

Having an educational leadership role (program director, etc)

Investigating and publishing on education-related topics

Which of these activities do you see as the primary meaning of "medical education"?

Supervising medical students/trainees in a clinical capacity

Teaching medical students/trainees in a classroom or other formal curricular setting (non-clinical)

Mentorship/career development for medical students/trainees

Investigating and publishing on education-related topics

Having an educational leadership role (program director, etc)

Other

What importance does being an educator have to you currently (during fellowship)?

Not important at all

Slightly important

Moderately important

Extremely important

What level of importance do you think being an educator will have in your future career plans? 
Not important at all

Slightly important

Moderately important

Extremely important

Have you received formal training in medical education?

Yes

No

What type of formal training in medical education have you received?

Coursework

Certificate program

Graduate degree

Do you think formal training in medical education should be required for those pursuing a career as a medical educator or clinician-educator?

Yes

No

\section{References}

1. Julian KA, O'Sullivan PS, Vener MH, Wamsley MA. Teaching residents to teach: The impact of a Multi-Disciplinary Longitudinal Curriculum to Improve Teaching Skills.

2. Pessegueiro AM, Kipps K, Friedman J. Training residents for future careers in medical education. Med Educ 2018; 52(5): 565-66.

3. Ahn J, Martin SK, Farnan JM, Fromme HB. The Graduate Medical Education Scholars Track: Developing Residents as Clinician-Educators during clinical training via a longitudinal, multimodal, and multidisciplinary track. Acad Med2018; 93(2): 214-19.

4. Rosenbaum ME, Rowat JA, Ferguson $\mathrm{KJ}$ et al. Developing future faculty: a program targeting internal medicine fellows' teaching skills. J Grad Med Educ2011; 3(3): 302-8. 
5. Richards JB, Kelly E, Fessler H, Roberts DH. A novel survey tool to assess pulmonary and critical care fellows' attitudes regarding acquiring teaching skills during fellowship training. J Grad Med Educ2013; 5(3): 506-9.

6. Adamson R, Goodman RB, Kritek P, et al. Training the teachers. The clinician-educator track of the University of Washington Pulmonary and Critical Care Medicine Fellowship Program. Ann Am Thorac Soc2015; 12(4): 480-85.

7. Horn L, Tzanetos K, Thorpe K, Straus SE. Factors associated with the subspecialty choices of internal medicine residents in Canada. BMC Med Educ2008; 8:37.

8. Marshall AL, Jenkins S, Mikhael J, Gitlin SD. Determinants of hematology-oncology trainees' postfellowship career pathways with a focus on nonmalignant hematology. Blood Adv 2018; 2(4): 361-69.

9. Miloslavsky EM, Boyer D, Winn AS et al. Fellows as Teachers: Raising the Educational Bar. Ann Am Thorac Surg 2016; 13(4): 465-68.

10. Miloskavsky EM, McSparron JI, Dengan KO et al. The Fellow as Clinical Teacher Curriculum: Enhancing Teaching in the Setting of Consultation. J Grad Med Educ2015; 7(2): 281-2.

11. Chen HC, Wamsley MA, Azzam A et al. The Health Professions Education Pathway: Preparing students, residents and fellows to become future educators. Teach Learn Med2017; 29(2): 216-27.

12. Alpert CM, Sinha SS, Cullen MW. Teaching Tomorrow's Teachers: An Innovative Model of ClinicianEducator Development for Fellows-in-Training. J Am Coll Cardiol 2019; 73(22); 2900-03.

13. Richards JB, McCallister JW, Lenz PH. Pulmonary and Critical Care Medicine Program Directors' Attitudes toward Training in Medical Education. A Nationwide Survey Study. Ann Am Thorac Soc 2016; 13(4): 475-80.

14. McSparron JI, Huang GC, Miloslavsky EM. Developing internal medicine subspecialty fellows' teaching skills: a needs assessment. BMC Med Educ2018; 18(1): 221.

\section{Supplementary Files}

This is a list of supplementary files associated with this preprint. Click to download.

- SurveyQuestionsSupplementalFile.docx 